\title{
COMMENTARY
}

\section{Cell-free DNA and outcome in sepsis}

\author{
Andrew Rhodes* and Maurizio Cecconi \\ See related research by Dwivedi et al., http://ccforum.com/content/16/4/R151/abstract
}

\begin{abstract}
Severe sepsis can be a catastrophic condition that is often associated with poor outcomes. The early diagnosis and management of the condition are vital in order to improve the chances of survival. However, owing to the syndromal nature of its definition and the lack of a biomarker able to accurately confirm the condition, the diagnosis of sepsis is challenging. Even more challenging is the prediction of how these patients will respond to the therapy and whether they will survive the intensive care and the hospital admission.
\end{abstract}

The search for a biochemical marker that can be used to confirm infection and sepsis - much like troponin is used to diagnose myocardial injury [1] - has been the source of a great deal of work. Many different compounds have been assessed either to diagnose the condition or to prognosticate between a good and a poor outcome in patients in whom the problem has already been diagnosed. These include acute-phase proteins such as $\mathrm{C}$ reactive protein [2], procalcitonin, inflammatory (proand anti-) cytokines, cell surface proteins (adhesion molecules, for instance), and markers of coagulation and apoptosis [3].

The ideal biomarker should possess a number of properties: it should have a high sensitivity for the disease process being detected, it should be very specific (that is, it should not be present if the disease is absent), its levels should reflect the severity of the condition, it should have a time course that allows the clinical evolution of the disease to be detected early, it should have a half-life that enables raised levels to remain in a clinically useful time frame and then decrease to enable tracking of severity, it should provide independent information on outcome, and it should be reproducible and, of course, cheap and

*Correspondence: andyr@sgul.ac.uk

Department of Intensive Care Medicine, St George's Healthcare NHS Trust and St George's University of London, London, SW19 0QT, UK easy to measure. Very few of the available biomarkers possess all of these qualities. If an ideal biomarker were found, however, we would have a tool that would help us to diagnose sepsis early and, in turn, enable us to direct evidence-based interventions directly toward the appropriate groups. In addition, this biomarker would enable clinical trials to be performed on homogenous patient groups of a comparable risk severity and, in turn, improve patient selection and therefore hopefully increase the likelihood of positive (or negative) results.

In recent years, free circulating nucleic acids in plasma and serum have been studied as biomarkers [4]. Free circulating DNA - cell-free DNA (cfDNA) - is released from a number of cells, including neutrophils, eosinophils, and macrophages, as a result of either apoptosis or other forms of cellular damage [5]. A couple of important considerations have to be made in order to understand the possible clinical impact of this biomarker. First, levels of cfDNA are detectable in healthy individuals; second, raised levels are not specific to a single disease. Nevertheless, raised levels of cfDNA have been shown, in a number of studies, to be extremely sensitive and specific for poor outcomes. cfDNA has been shown to have prognostic relevance in many conditions, including trauma [6], stroke [7], cancer, diabetes mellitus, sickle cell disease, organ transplantation [4], and critical illness [8-10].

In the previous issue of Critical Care, Dwivedi et al. [11] confirmed the prognostic abilities of cfDNA in severe sepsis. In a retrospective observational study of 80 patients with severe sepsis, the authors were able to show that cfDNA at baseline had a remarkable discriminatory power to predict intensive care mortality and, to a lesser (though still impressive) extent, hospital mortality. cfDNA performed a lot better than any of the available severity of illness or organ dysfunction scoring systems and also a lot better than interleukin-6, thrombin, and protein $C$. Indeed, the addition of these other markers added very little to the overall results. A cutoff level of cfDNA at baseline of $2.35 \mathrm{ng} / \mu \mathrm{L}$ had a sensitivity of $88 \%$ and a specificity of $94 \%$ for predicting intensive care unit mortality.

At least in terms of prediction in intensive care, these results are very similar to those of studies by Rhodes et 
al. [8], Butt et al. [9], and Saukkonen et al. [10] in mixed critical illness and sepsis and by Lo et al. [6] in trauma. In each of these studies, the presence of increased levels of this marker had very significant abilities to predict overall outcome from the disease being treated. Another thing these studies have in common, however, is that they are all on relatively small samples of patients, and it is gratifying to see that Dwivedi et al. already have a grant to complete a larger confirmatory study. We await the results eagerly.

Several questions do need to be considered, however. Raised levels have been detected in a number of different diseases [12] and interventions (for instance, hemodialysis [13]) that are all too often present in patients with sepsis. Which of the two are leading to the raised levels or the sepsis per se: the underpinning diseases or the interventions? In addition, what is the additive effect of the interventions on a complicated patient requiring multiple organ supports? In a separate issue, the fact that the results suggest that outcome can be predicted at baseline does raise an important concern. Does this mean that, if cfDNA is already elevated when we start to treat these patients, the chances of survival will not be affected by our treatment? Or even worse, does it mean that some patients already have a predetermined outcome when they present to us for treatment? If so, what is the effect of our current managements and supports? If this is the case, then the implications for how the information would be used are profound.

In the studies performed to date, circulating cell-free nucleic acids seem to be among the more promising prognostic markers that could be used in severe sepsis. The studies do need replicating, however, and the assays need standardizing and would need to be made more user-friendly. Only then could we consider measuring this as a routine in our patients, and even then, we would need some careful thoughts about how to act upon the information obtained. This new information would enable better selection for clinical trials but also may have a far wider potential as a routine part of our clinical investigation and management.
Abbreviation

cfDNA, cell-free DNA.

\section{Competing interests}

The authors declare that they have no competing interests.

Published: 8 November 2012

\section{References}

1. Kehl DW, lqbal N, Fard A, Kipper BA, De La Parra Landa A, Maisel AS: Biomarkers in acute myocardial injury. Trans/ Res 2012, 159:252-264.

2. Al-Subaie N, Reynolds T, Myers A, Sunderland R, Rhodes A, Grounds RM, Hall GM: C-reactive protein as a predictor of outcome after discharge from the intensive care: a prospective observational study. $\mathrm{Br} J$ Anaesth 2010, 105:318-325.

3. Pierrakos C, Vincent J-L: Sepsis biomarkers: a review. Crit Care 2010, 14:R15.

4. Butt AN, Swaminathan R: Overview of circulating nucleic acids in plasma/ serum. Ann N Y Acad Sci 2008, 1137:236-242.

5. Huttunen R, Kuparinen T, Jylhävä J, Aittoniemi J, Vuento R, Huhtala H, Laine J, Syrjänen J, Hurme M: Fatal outcome in bacteremia is characterized by high plasma cell free DNA concentration and apoptotic DNA fragmentation: a prospective cohort study. PLOS ONE 2011, 6:e21700

6. Lo YM, Rainer TH, Chan LY, Hjelm NM, Cocks RA: Plasma DNA as a prognostic marker in trauma patients. Clin Chem 2000, 46:319-323.

7. Rainer TH, Wong KS, Lam W, Lam NYL, Graham CA, Lo YMD: Comparison of plasma beta-globin DNA and S-100 protein concentrations in acute stroke. Clin Chim Acta 2007, 376:190-196.

8. Rhodes A, Wort SJ, Thomas H, Collinson P, Bennett ED: Plasma DNA concentration as a predictor of mortality and sepsis in critically ill patients. Crit Care 2006, 10:R60.

9. Wijeratne S, Butt A, Burns S, Sherwood K, Boyd O, Swaminathan R: Cell-free plasma DNA as a prognostic marker in intensive treatment unit patients. Ann N Y Acad Sci 2004, 1022:232-238.

10. Saukkonen K, Lakkisto P, Pettila V, Varpula M, Karlsson S, Ruokonen E, Pulkki K: Cell-free plasma DNA as a predictor of outcome in severe sepsis and septic shock. Clin Chem 2008, 54:1000-1007.

11. Dwivedi DJ, Toltl LJ, Swystun LJ, Pogue J, Liaw KL, Weitz Jl, Cook DJ, FoxRobichaud AE, Liaw PC and Canadian Critical Care Translational Biology Group: Prognostic utility and characterization of cell-free DNA in patients with severe sepsis. Crit Care 2012, 16:R151.

12. Rainer TH, Chan AKC, Lee LLY, Yim VWT, Lam NYL, Yeung SW, Graham CA, Lo DYM: Use of plasma DNA to predict mortality and need for intensive care in patients with abdominal pain. Clin Chim Acta 2008, 398:113-117.

13. Tovbin D, Novack V, Wiessman MP, Elkadir AA, Zlotnik M, Douvdevani A: Circulating cell-free DNA in hemodialysis patients predicts mortality. Nephrol Dial Transplant 2012 Jul 24 [Epub ahead of print]

doi:10.1186/cc11508

Cite this article as: Rhodes A, Cecconi M: Cell-free DNA and outcome in sepsis. Critical Care 2012, 16:170. 